\title{
Management of secondary chronic headache in the general population: the Akershus study of chronic headache
}

\author{
Espen Saxhaug Kristoffersen ${ }^{1,2^{*}}$, Christofer Lundqvist ${ }^{1,3,4}$, Kjersti Aaseth$^{1}$, Ragnhild Berling Grande ${ }^{1}$ \\ and Michael Bjørn Russell ${ }^{1,3}$
}

\begin{abstract}
Background: The prevalence of secondary chronic headache in our population is $0.5 \%$. Data is sparse on these types of headache and information about utilisation of health care and medication is missing. Our aim was to evaluate utility of health service services and medication use in secondary chronic headache in the general population.
\end{abstract}

Methods: An age and gender stratified cross-sectional epidemiological survey included 30,000 persons 30-44 years old. Diagnoses were interview-based. The International Classification of Headache Disorders $2^{\text {nd }} \mathrm{ed}$. was applied along with supplementary definitions for chronic rhinosinusitis and cervicogenic headache. Secondary chronic headache exclusively due to medication overuse was excluded.

Results: One hundred and thirteen participants had secondary chronic headache. Thirty \% had never consulted a physician, 70\% had consulted their GP, 35\% had consulted a neurologist and 5\% had been hospitalised due to their secondary chronic headache. Co-occurrence of migraine or medication overuse increased the physician contact. Acute headache medication was taken by $84 \%$ and $11 \%$ used prophylactic medication. Complementary and alternative medicine was used by $73 \%$ with the higher frequency among those with than without physician contact.

Conclusion: The pattern of health care utilisation indicates that there is room for improving management of secondary chronic headache.

Keywords: Secondary chronic headache, Chronic migraine, Medication-overuse headache, Health care utilisation, General population

\section{Background}

The WHO initiated 'Lifting the burden: the global campaign to reduce the burden of headache' because headache is common, under-diagnosed and undertreated [1-3].

The International Classification of Headache Disorders $2^{\text {nd }}$ edition (ICHD-II) provides diagnostic criteria for headaches which are divided into primary and secondary forms [4].

\footnotetext{
* Correspondence: e.s.kristoffersen@medisin.uio.no

${ }^{1}$ Head and Neck Research Group, Research Centre, Akershus University

Hospital, PO Box 95, 1478, Lørenskog, Norway

${ }^{2}$ Department of General Practice, Institute of Health and Society, University of

Oslo, Oslo, Norway

Full list of author information is available at the end of the article
}

The most common acute secondary headaches are induced by alcohol, fever, hunger and rhinosinusitis and are usually paroxysmal [5], but secondary chronic headache ( $\geq 15$ days per month $\geq 3$ months or $\geq 180$ days/last year) is also common and medication overuse contributes to the problem [6,7].

Most headaches are self-managed [8], but headache is also one of the most common reasons for consulting a general practitioner (GP) and accounts for $4 \%$ of all GP consultations in the UK $[9,10]$. Approximately $20-30 \%$ of all new referrals to out-patients neurological departments are due to headache [9-12].

Headache has been suggested to be the most common new neurological symptom presented [13], and many 
neurological conditions include headache in the symptomatology, thus it also represents an important neurological differential diagnosis and may cause high use of health care services.

Epidemiological data on secondary headaches are largely lacking, and most information are from studies that have not had a main focus on secondary chronic headache. The International Headache Society`s classification committee encourages further research in order to provide more knowledge and information of secondary headaches $[4,14]$.

We have previously described the management of primary chronic headaches in the general population [15]. Our aim here was to investigate secondary chronic headache in the general population in order to evaluate utility of health services and medication use.

\section{Methods}

Figure 1 shows a flow-chart of the study. The method has been described in more detail elsewhere $[6,15]$.

\section{Sampling}

A random age-stratified sample of 15000 men and 15000 women, 30-44 years old and residing in the 20 eastern municipalities in Akershus County, was drawn from the National Personal Registry by Statistics Norway. Akershus County has both rural and urban areas and is situated in close proximity to Oslo.

\section{Questionnaire}

All persons in the sample received a mailed questionnaire with a standard letter containing information

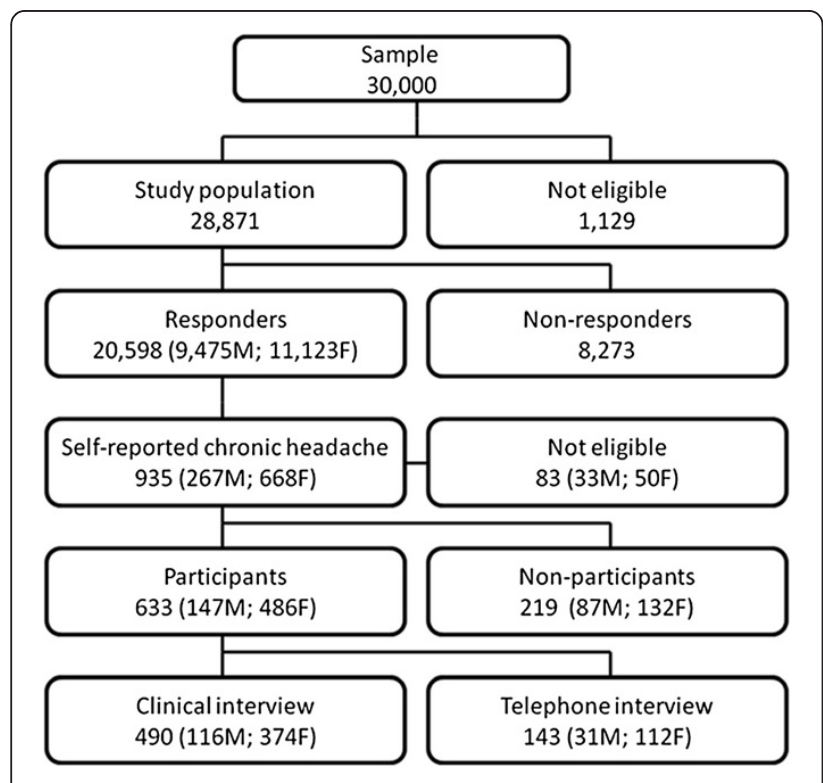

Figure 1 Flow chart of the participation. about the project. Apart from ensuring confidentiality and emphasizing the importance of participation, it was stated that the object was to study headache. The questions 'How many days during the last month have you had headache?' and 'How many days during the last year have you had headache?' were used to screen for chronic headache. If the questionnaire evoked no response, a second and subsequently a third reminder were issued.

\section{Clinical interview, physical and neurological examination}

The study took place at the Akershus University Hospital in 2005. Persons with self-reported chronic headache who also consented by adding their telephone number on the questionnaire were invited to a clinical examination. Self-reported chronic headache was defined to be headache occurring $\geq 15$ days within the last month and/or headache occurring $\geq 180$ days within the last year. Inclusion required Norwegian languages skills. Two neurological residents (RBG and KA) experienced in headache diagnostics conducted all interviews and the physical and neurological examinations. Those unable to meet at the clinic were interviewed by telephone.

\section{Headache classification}

All headaches were classified according to explicit diagnostic criteria of the ICHD-II and its relevant revisions [4,16-18]. Those with secondary chronic headache exclusively due to medication overuse were excluded.

We defined secondary chronic headache as secondary headache $\geq 15$ days/month for at least 3 months, as the ICHD-II do not provide an explicit definition of frequency for secondary headaches. A more detailed description has been published elsewhere $[6,19]$.

Chronic post-traumatic headache $(\mathrm{CPTH})$ included head and whiplash traumas.

Cervicogenic headache $(\mathrm{CEH})$ was classified according to the criteria of the Cervicogenic Headache International Study Group, requiring at least three criteria to be fulfilled not including blockade of the neck due to the noninterventional nature of our study (Table 1) [20].

Headache attributed to chronic rhinosinusitis (HACRS) was defined according to the criteria established by the American Academy of Otolaryngology - Head and Neck Surgery (Table 2) [21] adding that the symptoms had persisted 12 weeks or more. Those with suspected HACRS were examined with anterior rhinoscopy and completed the Sino-Nasal questionnaire (SNOT-20) [22].

Pregnancy related headache is not an ICHD-II diagnosis unless it is associated with eclampsia. We included 4 women who experienced headache exclusively during pregnancy. Two women had chronic headache $>3$ months associated with pre-eclampsia, one had had headache during all 3 pregnancies and one had headache during her first pregnancy. 
Table 1 Definition of cervicogenic headache [20]

\begin{tabular}{|c|c|}
\hline \multirow[t]{8}{*}{ Major criteria } & I. Symptoms and signs of neck involvement \\
\hline & la. Precipitation of head pain, similar to the usually occurring one: \\
\hline & la1) by neck movement and/or sustained, awkward head positioning, and/or: \\
\hline & la2) by external pressure over the upper cervical or occipital region on the symptomatic side. \\
\hline & Ib. Restriction of the range of motion (ROM) in the neck. \\
\hline & $\begin{array}{l}\text { Ic. Ipsilateral neck, shoulder or arm pain of a rather vague, non-radicular nature, or - occasionally - arm pain of a } \\
\text { radicular nature. }\end{array}$ \\
\hline & II. Confirmatory evidence by diagnostic anaesthetic blockades. \\
\hline & III. Unilaterality of the head pain, without sideshift. \\
\hline Head pain characteristics & $\begin{array}{l}\text { IV. Moderate-severe, non-throbbing pain, usually starting in the neck. Episodes of varying duration, or: fluctuating, } \\
\text { continuous pain. }\end{array}$ \\
\hline $\begin{array}{l}\text { Other characteristics of some } \\
\text { importance }\end{array}$ & $\begin{array}{l}\text { V. Only marginal effect or lack of effect of indomethacin. Only marginal effect or lack of effect of ergotamine and } \\
\text { sumatriptan. Female sex. Not infrequent occurrence of head or indirect neck trauma by history, usually of more } \\
\text { than only medium severity. }\end{array}$ \\
\hline $\begin{array}{l}\text { Other features of lesser } \\
\text { importance }\end{array}$ & $\begin{array}{l}\text { VI. Various attack-related phenomena, only occasionally present, and/or moderately expressed when present: } \\
\text { a) nausea, b) phono- and photophobia, c) dizziness, d) ipsilateral "blurred vision", e) difficulties swallowing, f) } \\
\text { ipsilateral oedema, mostly in the periocular area. }\end{array}$ \\
\hline
\end{tabular}

It is obligatory that one or more of the phenomena la-lc are present.

\section{Physician consultation}

We defined four levels of contact due to headache, i.e. none (no physician contact), primary (GP), secondary (neurologist) and tertiary (hospitalisation). In Norway, a GP referral is a prerequisite for access to neurologists, while both GPs and neurologists can refer to the hospital.

\section{Complementary and alternative medicine (CAM) contacts}

The CAM forms queried were acupuncture, chiropractic, homeopathy, naprapathy, physiotherapy, psychologist and psychomotor physiotherapy.

\section{Medication use and dependency}

We asked about current medication use, and excluded medication used for other pain conditions. Medication overuse was defined according to the ICHD-II criteria for medication overuse headache (i.e. $\geq 15$ days per month for simple analgesics and $\geq 10$ days per months for triptans and ergotamines) [4,17].

To assess dependency-like behaviour in relation to headache medication, we used the SDS, which includes five questions designed to measure psychological dependence $[23,24]$. The questions apply to the headache medication taken within the last month. Each item is scored on a 4-point scale (0-3), and the total maximum score is 15 . The method has been described in detail elsewhere [24].

\section{Data processing}

Data from the interviews were directly entered using SPSS Data Entry 4.0 (SPSS Inc., Chicago, IL, USA) and statistical analyses were performed using SPSS 20.00 (SPSS Inc., Chicago, IL, USA). For descriptive data, proportions, means and confidence intervals $(\mathrm{CI})$ are given. Pearson $\chi^{2}$ test was used for testing significance of group differences for categorical data, Fisher`s exact test was used when appropriate. Student's T-test was used for numerical data. Significance levels were set at $\mathrm{p}<0.05$ and $95 \% \mathrm{CI}$ were calculated. CI and probabilities are not given when $\mathrm{n}<5$.

\section{Ethical issues}

The Regional Committee for Medical Research Ethics and the Norwegian Social Science Data Services approved the study. All participants gave informed consent.

Table 2 Definition of rhinosinusitis by the American Academy of Otolaryngology - Head and Neck Surgery [21]

\begin{tabular}{|c|c|}
\hline \multirow[t]{6}{*}{ Major factors } & Facial pain/pressure \\
\hline & Nasal obstruction/blockage \\
\hline & Nasal discharge/purulence/discolored postnasal drainage \\
\hline & Hyposmia/anosmia \\
\hline & Purulence in nasal cavity on examination \\
\hline & Fever (acute rhinosinusitis) \\
\hline \multirow[t]{7}{*}{ Minor factors } & Headache \\
\hline & Fever (all nonacute) \\
\hline & Halitosis \\
\hline & Fatigue \\
\hline & Dental pain \\
\hline & Cough \\
\hline & Ear pain/pressure/fullness \\
\hline
\end{tabular}

Two major factors or one major and two minor factors are required for the diagnosis. Of note, facial pain requires another major factor associated with it for diagnosis, as facial pain plus two minor factors is not deemed sufficient for diagnoses of rhinosinusitis. 
Table 3 Contact and treatment pattern in relation to secondary headache diagnoses

\begin{tabular}{|c|c|c|c|c|c|c|c|c|c|c|c|c|c|c|c|}
\hline & $\begin{array}{l}\text { CPTH without } \\
\text { medication } \\
\text { overuse } \\
(\mathrm{N}=25)\end{array}$ & $\begin{array}{l}\text { CPTH with } \\
\text { medication } \\
\text { overuse } \\
(\mathrm{N}=22)\end{array}$ & $\begin{array}{c}\text { All } \\
\text { CPTH } \\
(\mathrm{N}=47)\end{array}$ & $\begin{array}{c}\text { CEH } \\
\text { without } \\
\text { medication } \\
\text { overuse } \\
(\mathrm{N}=12)\end{array}$ & $\begin{array}{l}\text { CEH with } \\
\text { medication } \\
\text { overuse } \\
(\mathrm{N}=12)\end{array}$ & $\begin{array}{c}\text { All } \\
\text { CEH } \\
(\mathrm{N}=24)\end{array}$ & $\begin{array}{l}\text { HACRS without } \\
\text { medication } \\
\text { overuse } \\
(\mathrm{N}=22)\end{array}$ & $\begin{array}{l}\text { HACRS with } \\
\text { medication } \\
\text { overuse } \\
(\mathrm{N}=24)\end{array}$ & $\begin{array}{c}\text { All } \\
\text { HACRS } \\
(\mathrm{N}=46)\end{array}$ & $\begin{array}{l}\text { Other } \\
\text { secondary } \\
\text { chronic } \\
\text { headache } \\
\text { without } \\
\text { medication } \\
\text { overuse } \\
(\mathrm{N}=8)\end{array}$ & $\begin{array}{c}\text { Other } \\
\text { secondary } \\
\text { chronic } \\
\text { headache } \\
\text { with } \\
\text { medication } \\
\text { overuse } \\
(\mathrm{N}=1)\end{array}$ & $\begin{array}{c}\text { All } \\
\text { Other } \\
\text { secondary } \\
\text { chronic } \\
\text { headache } \\
(\mathrm{N}=9)\end{array}$ & $\begin{array}{c}\text { All } \\
\text { secondary } \\
\text { chronic } \\
\text { headaches } \\
\text { without } \\
\text { medication } \\
\text { overuse } \\
(\mathrm{N}=58)\end{array}$ & $\begin{array}{c}\text { All } \\
\text { secondary } \\
\text { chronic } \\
\text { headaches } \\
\text { with } \\
\text { medication } \\
\text { overuse } \\
(\mathrm{N}=55)\end{array}$ & $\begin{array}{c}\text { All } \\
\text { secondary } \\
\text { chronic } \\
\text { headaches } \\
(\mathrm{N}=113)\end{array}$ \\
\hline & $\%(n)$ & $\%(n)$ & $\%(n)$ & $\%(n)$ & $\%(n)$ & $\%(n)$ & $\%(\mathbf{n})$ & $\%(n)$ & $\%(n)$ & $\%(n)$ & $\%(n)$ & $\%(n)$ & $\%(n)$ & $\%(n)$ & $\%(n)$ \\
\hline \multicolumn{16}{|l|}{ Contact level } \\
\hline None & $28(7)$ & $18(4)$ & $23(11)$ & $42(5)$ & 25 (3) & $33(8)$ & $36(8)$ & $17(4)$ & $26(12)$ & $63(5)$ & $0(0)$ & $56(5)$ & $41(24)$ & $18(10)$ & $30(34)$ \\
\hline Primary & $72(18)$ & $82(18)$ & $77(36)$ & $58(7)$ & $75(9)$ & $67(16)$ & $64(14)$ & $83(20)$ & $74(34)$ & $38(3)$ & $100(1)$ & $44(4)$ & $59(34)$ & $82(45)$ & $70(79)$ \\
\hline Secondary & $40(10)$ & 59 (13) & $49(23)$ & $8(1)$ & $50(6)$ & $29(7)$ & $27(6)$ & $29(7)$ & $28(13)$ & $0(0)$ & $100(1)$ & $11(1)$ & $28(16)$ & $44(24)$ & $35(40)$ \\
\hline Tertiary & $8(2)$ & $5(1)$ & $6(3)$ & $0(0)$ & $8(1)$ & $4(1)$ & $5(1)$ & $4(1)$ & $4(2)$ & $0(0)$ & $100(1)$ & $11(1)$ & $5(3)$ & $5(3)$ & $5(6)$ \\
\hline \multicolumn{16}{|c|}{ Complementary and alternative medicine } \\
\hline Acupuncture & $52(13)$ & $55(12)$ & $53(25)$ & $58(7)$ & $33(4)$ & $46(11)$ & $36(8)$ & $38(9)$ & $37(17)$ & $13(1)$ & $0(0)$ & $11(1)$ & $41(24)$ & $42(23)$ & $42(47)$ \\
\hline Chiropractic & $40(10)$ & $59(13)$ & $49(23)$ & $33(4)$ & $33(4)$ & $33(8)$ & $27(6)$ & $33(8)$ & $30(14)$ & $0(0)$ & $0(0)$ & $0(0)$ & $29(17)$ & $42(23)$ & $35(40)$ \\
\hline Homeopathy & $12(3)$ & $23(5)$ & $17(8)$ & $25(3)$ & $8(1)$ & $17(4)$ & $14(3)$ & $17(4)$ & $15(7)$ & $0(0)$ & $0(0)$ & $0(0)$ & $12(7)$ & $16(9)$ & $14(16)$ \\
\hline Naprapathy & $4(1)$ & $9(2)$ & $6(3)$ & $0(0)$ & $8(1)$ & $4(1)$ & $0(0)$ & $0(0)$ & $0(0)$ & $0(0)$ & $0(0)$ & $0(0)$ & $2(1)$ & $4(2)$ & $3(3)$ \\
\hline Physiotherapy & $72(18)$ & $100(22)$ & $85(40)$ & $75(9)$ & $75(9)$ & 75 (18) & $36(8)$ & $58(14)$ & $48(22)$ & $25(2)$ & $100(1)$ & $33(3)$ & $52(30)$ & $76(42)$ & $64(72)$ \\
\hline Psychologist & $4(1)$ & $0(0)$ & $2(1)$ & $0(0)$ & $0(0)$ & $0(0)$ & $5(1)$ & $8(2)$ & 7 (3) & $0(0)$ & $0(0)$ & $0(0)$ & $2(1)$ & $4(2)$ & $2(2)$ \\
\hline $\begin{array}{l}\text { Psychomotor } \\
\text { physiotherapy }\end{array}$ & $4(1)$ & $5(1)$ & $4(2)$ & $0(0)$ & $8(1)$ & $4(1)$ & $0(0)$ & $4(1)$ & $2(1)$ & $0(0)$ & $0(0)$ & $0(0)$ & $2(1)$ & $5(3)$ & $4(4)$ \\
\hline Any CAM & 76 (19) & $100(22)$ & $87(41)$ & $75(9)$ & $83(10)$ & 79 (19) & 64 (14) & 67 (16) & $65(30)$ & $25(2)$ & $100(1)$ & $33(3)$ & 64 (37) & $82(45)$ & $73(82)$ \\
\hline \multicolumn{16}{|c|}{ Medication use } \\
\hline $\begin{array}{l}\text { Acute } \\
\text { medication }\end{array}$ & $68(17)$ & $100(22)$ & $83(39)$ & $75(9)$ & $100(12)$ & $88(21)$ & $82(18)$ & $100(24)$ & $91(42)$ & $50(4)$ & $100(1)$ & $56(5)$ & $69(40)$ & $100(55)$ & $84(95)$ \\
\hline $\begin{array}{l}\text { Prophylactic } \\
\text { medication }\end{array}$ & $16(4)$ & $14(3)$ & $15(7)$ & $8(1)$ & $17(2)$ & $13(3)$ & $5(1)$ & $13(3)$ & $9(4)$ & $0(0)$ & $0(0)$ & $0(0)$ & $9(5)$ & $13(7)$ & $11(12)$ \\
\hline
\end{tabular}

CPTH Chronic post-traumatic headache; CEH Cervicogenic headache; HACRS Headache attributed to chronic rhinosinusitis.

The diagnoses are not mutually exclusive, i.e. one person can have two or more headache diagnoses. 


\section{Results}

Participants and headache diagnoses

The questionnaire response rate was $71 \%$ and the interview participation rate was $74 \%$. Among the participants, $82 \%(93 / 113)$ had an interview and a physical and neurological examination at the clinic, whereas $18 \%(20 / 113)$ had an interview by telephone. Whether the participants had been interviewed in person or by phone made no difference to the frequency of the various headache diagnoses, medication use, medication overuse, physician or CAM contact.

A total of 113 participants (22\% men and $78 \%$ women) had secondary chronic headaches not exclusively due to medication overuse.

Forty-two \% had CPTH, 21\% had CEH, 41\% HACRS and $8 \%$ had other secondary chronic headache, i.e. 3 post-craniotomy, 1 diving related, 4 pregnancy related, and 1 post-meningitis.

The sum exceeds $100 \%$, since the diagnoses are not mutually exclusive. Forty-one\% had co-occurrence of migraine and $49 \%$ had co-occurrence of medication overuse.

\section{Physician consultation pattern}

Table 3 shows the physician contact pattern.

Thirty \% (34/113) had never had contact with the health care system for their secondary chronic headache, while $70 \%(79 / 113)$ had had contact with their GP, 35\% (40/113) had been referred to a neurologist and 5\% (6/113) had been hospitalised for their secondary chronic headache. There was no gender difference in the physician contact pattern.

\section{Complementary and alternative medicine}

Table 3 shows that 73\% (82/113) had used CAM for their secondary chronic headache. Physiotherapy, acupuncture and chiropractic were most frequently used. Physiotherapy was most commonly used in $\mathrm{CPTH}, \mathrm{CEH}$ and HACRS, i.e. $85 \%, 75 \%$ and $48 \%$, respectively.

The use of CAM was significantly higher among those who had consulted a physician compared to those who had not (84\% vs. $47 \%, \mathrm{p}<0.001)$.

\section{Co-occurrence of migraine}

Co-occurrence of migraine increased health care utilisation (physician contact $(\mathrm{p}=0.043)$, and hospitalisation $(\mathrm{p}=0.04))$.

The overall use of CAM was not significantly influenced by migraine, although there was a tendency for a higher usage of CAM among people with than without co-occurrence of migraine.

\section{Use of medication}

Acute medication was used by $84 \%$, and $19 \%$ used it on a daily basis. A higher proportion of participants with than without co-occurrence of migraine used acute medication ( $93 \%$ vs. $78 \%, \mathrm{p}=0.024)$, while there was no gender difference. People using acute medication had significantly more physician contact than people not using acute medication ( $89 \%$ vs. $74 \%, \mathrm{p}=0.045$ ). People using acute medication had significantly more CAM use than people not using acute medication (89\% vs. $71 \%$, $\mathrm{p}=0.019$ ).

Contact with physicians was significantly influenced by medication overuse ( $82 \%$ vs. $59 \%, \mathrm{p}=0.007)$, and proportions with none, primary and secondary physician contact level was also different for those with compared to those without medication overuse (Figure 2). A higher proportion of those with than without medication overuse used CAM ( $82 \%$ vs. $64 \%, p=0.032$ ). The distribution of medication overuse was similar in different subtypes of secondary chronic headaches. Fifty-eight\% overused simple analgesics, mainly paracetamol and/or ibuprofen and 31\% overused combination analgesics, usually a combination of paracetamol and codeine. Of the latter 53\% also overused simple analgesics. The physician contact level was not influenced by type of medication overuse. The SDS score was significantly higher in those with than without medication overuse for all levels of physician contact (Figure 3).

Prophylactic treatment was used by $11 \%(12 / 113)$ and was not influenced by gender or co-occurrence of migraine.

\section{Discussion}

\section{Presentation of main findings}

Two-thirds of those with secondary chronic headache consulted their GP for headache, and half of these had also consulted a neurologist. Approximately 40\% had cooccurrence of migraine, and approximately $50 \%$ had medication overuse. The majority used acute medication,

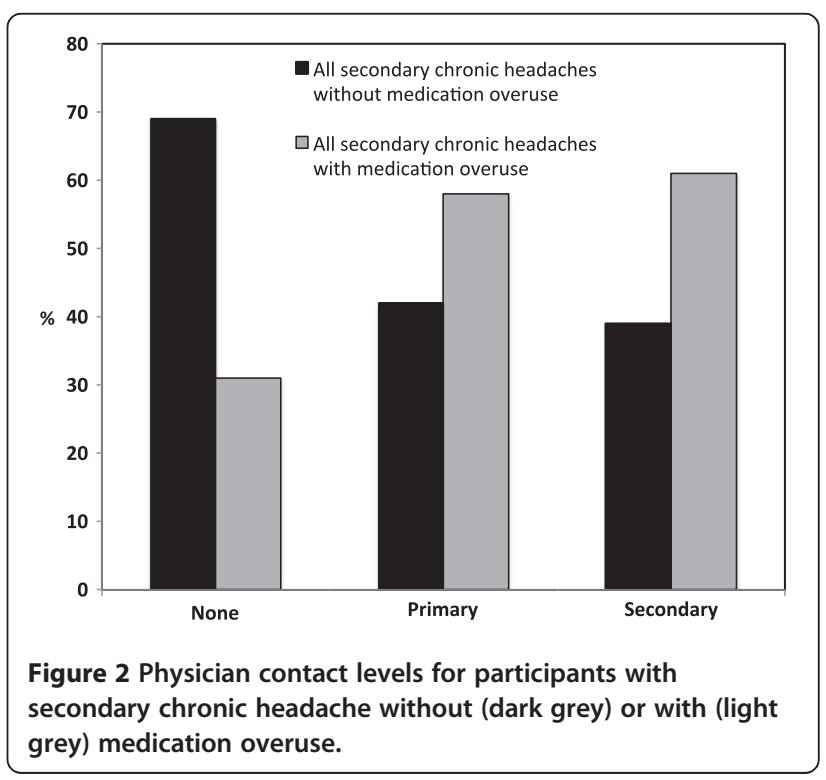




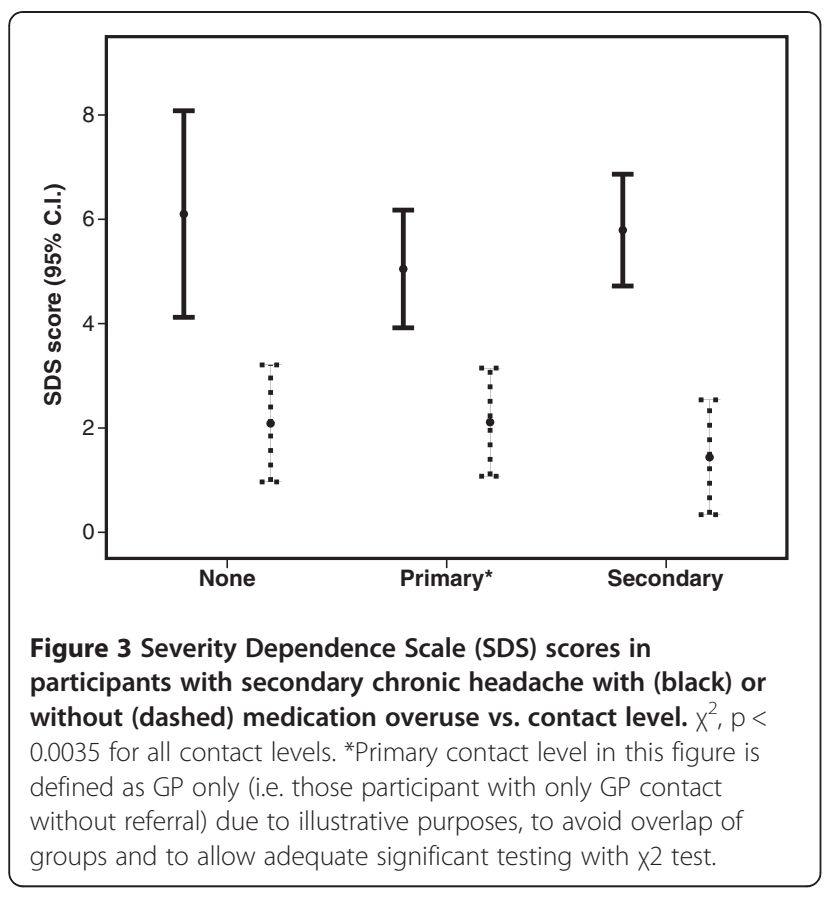

while prophylactic medication was rarely used. Medication use, medication overuse and high SDS score were associated with more physician contact, referral and use of CAM.

\section{Methodological considerations}

The present study is based on recruitment from the general population. The large sample and high response rate should ensure representativity. The secondary chronic headaches $\mathrm{CPTH}, \mathrm{CEH}$ and HACRS are frequent enough to ensure accurate descriptive statistics, while other types of secondary chronic headache are too infrequent for statistical analyses. The age range, though it may exclude some secondary headache types, was chosen explicitly to focus on a population without too much co-morbidity of non-headache disorders. Data from the Norwegian prescription registry indicate a high increase in drug prescriptions among people above 50 years [25]. This includes medication used for high blood pressure and pain killers for non-headache pain which both are is likely to influence the headache spectrum, a bias that we tried to avoid. Headache diagnoses are a challenge in people with chronic headache. To ensure precise diagnostic, two neurological residents experienced in headache diagnostics conducted all interviews. Complicated headache histories were discussed among the authors before classification. The different headache diagnoses were equally frequently by the two interviewers, suggesting that inter-observer variation was low. Whether the participants had been interviewed in person or by phone made no difference to the various outcomes. The ICHD-II classification of the secondary chronic headaches is a challenge since chronicity is not defined exhaustively [4]. Likewise, the diagnoses of $\mathrm{CEH}$ are not specific and the diagnosis HACRS is not part of the ICHD-II classification [20,21].

The data on medication use and health care utilisation are based on self-reports and therefore open to recall bias. Health registry data are, however, often incomplete and not necessarily more precise. Since there is no systematic registration of CAM, one has to rely on self-reports.

\section{Physician contact and use of complementary and alternative medicine}

Surprisingly, even though high levels of specialist contact, high medication use, medication overuse and high proportions of CAM contacts seem to suggest a difficult headache situation for many of our participants, as many as $1 / 3$ had no physician contact ever due to their headache. This figure is higher than the corresponding figure for primary chronic headaches where only $20 \%$ had no such contact [15]. This may be due to low expectations towards traditional medicine regarding secondary chronic headache, and/or on the contrary that secondary chronic headache is expected to be self-treatable. Another possible explanation might be that the secondary chronic headache is less disabling than migraine. Co-occurrence of migraine increased physician contact, and this might explain why some of those without co-occurrence of migraine rely on self-treatment for their secondary chronic headache.

The use of CAM was high in our population with secondary chronic headaches and the use of CAM was significantly higher among those who had consulted a physician compared to those who had not. We have no specific information on what the GPs and/or neurologists have done, but it is likely to assume that unsatisfactory pharmacological treatment lead to higher use of CAM. However, both pharmacological and CAM treatment followed the same pattern i.e. more medication use correlated with more CAM use. This suggests that some secondary chronic headache sufferers will try many treatment options to alleviate their headache.

The most frequent secondary chronic headaches (CPTH, CEH and HACRS) had surprisingly similar pattern of CAM use despite these are caused by different pathophysiological mechanisms. Physiotherapy was the most commonly used strategy in all these three groups, but to a much higher degree in people with $\mathrm{CPTH} / \mathrm{CEH}$ probably due to the fact that these people have more neck and muscular pain and tenderness than people with HACRS. Usage of acupuncture, chiropractic and homeopathy was remarkably similar between the three groups. In relation to HACRS, this may suggest that this entity is rarely recognised by people or diagnosed by 
either physicians or by those practicing CAM. An alternative may be that rhinosinusitis problems are commonly present in other conditions with secondary headache, either by coincidence or by interactions based on medication use or other causal or interactive relationships such as sensitisation processes. We have previously described that HACRS may have a better prognosis than $\mathrm{CPTH}$ and especially $\mathrm{CEH}$ which support HACRS as a different entity $[19,22]$. The improvement among participants with HACRS was seen especially in those who had interventions for their rhinosinusitis and who had reduced their nasal decongestants and their headache medication overuse [22]. This would seem to support the presence of HACRS as a chronic headache entity distinct from $\mathrm{CPTH}$ and $\mathrm{CEH}$ and that a focus and referral practice reflecting this by traditional school medicine physicians may give a hope for a more effective treatment for a group of sufferers from secondary chronic headache.

\section{Use of medication}

Use of acute headache medication is associated with physician contact and CAM treatment, but even at the "none" contact level more than $70 \%$ used acute headache medication. Altogether, almost $50 \%$ overused headache medication. In the most revised version of the headache classification this headache should be classified as probable $\mathrm{MOH}$ until detoxification has taken place, in which case it would be classified either as $\mathrm{MOH}$ (if improvement is seen) or as the remaining alternative, secondary chronic headache diagnosis (if no improvement is seen) [4,16-18]. However in a cross-sectional study such as the present one, both diagnoses must be given and a co-morbid situation considered. Medication overuse as well as SDS score related to the overuse was significantly associated with increasing contacts with health services, whether CAM or GPs/neurologists. Medication overuse seems to be either a marker of a complex chronic headache requiring increased support from the health services or causally associated with a worsening of the headache. The direction of causality of these associations cannot be determined in a cross-sectional study. The concept of medication overuse in secondary headaches is still debatable. Frequent use of medication, for instance, could be fully justified by a chronic inflammation or other conditions. In addition, the direction of a possibly causal association between medication overuse and the underlying headache becomes even more difficult to ascertain if the headache is assumed to be secondary to another, defined organic cause. However, simply the high co-occurrence of medication overuse seems to suggest the potential for trying detoxification also in the case of secondary chronic headaches. We have previously reported that reduced medication overuse is associated with improvement of CPTH and HACRS [19,22]. CEH did not improve after detoxification, but detoxification did not worsen the headache or have other negative effects [19].

In contrast to the high level of acute medication use stands the low level use of prophylactics. Which prophylactics that may be useful in secondary chronic headaches is not sufficiently described and should be addressed by further studies.

However, the $41 \%$ co-occurrence of migrainous headache may suggest a potential for using migraine prophylactics. It is suggested that migraineurs are undertreated and a substantial proportion of those who might benefit from migraine prevention do not receive it $[26,27]$.

\section{Conclusion}

Secondary chronic headache is a heterogeneous group of headache disorders with a high level of health care utilisation. The high level of neurologist contact, medication use/overuse and use of CAM indicate that this might be a complicated group to handle both in primary care and in neurologists setting. The treatment strategy should be focused on the type of secondary chronic headache. Detoxification of medication overuse is recommended and prophylactic treatment might also be effective, although the latter has not been documented in clinical trials.

\section{Competing interest}

The authors declare that they have no competing interest.

\section{Authors' contributions}

MBR had the original idea for the study and planned the overall design. ESK prepared the initial draft and was the main author of the present manuscript. RBG and KA collected data. $\mathrm{CL}$ and $\mathrm{MBR}$ was involved in data analysis and interpretation and assisted in preparation of the manuscript. All authors have read, revised and approved the final manuscript.

\section{Acknowledgments}

Akershus University Hospital kindly provided research facilities.

\section{Funding}

This study was supported by grants from the East Norway and South East Norway Regional Health Authority, Institute of Clinical Medicine, Campus Akershus University Hospital, University of Oslo and Institute of Health and Society, University of Oslo.

\section{Author details}

${ }^{1}$ Head and Neck Research Group, Research Centre, Akershus University Hospital, PO Box 95, 1478, Lørenskog, Norway. ²Department of General Practice, Institute of Health and Society, University of Oslo, Oslo, Norway. ${ }^{3}$ Institute of Clinical Medicine, Campus Akershus University Hospital, University of Oslo, Nordbyhagen, Norway. ${ }^{4} \mathrm{H} \varnothing \mathrm{KH}$, Research Centre, Akershus University Hospital, Lørenskog, Norway. ${ }^{5}$ Department of Neurology, Akershus University Hospital, Lørenskog, Norway.

Received: 13 November 2012 Accepted: 20 January 2013 Published: 30 January 2013

\section{References}

1. Steiner TJ (2004) Lifting the burden: the global campaign against headache. Lancet Neurol 3:204-205

2. Steiner TJ (2005) Lifting the burden: the global campaign to reduce the burden of headache worldwide. J Headache Pain 5:373-377 
3. Steiner TJ, Birbeck GL, Jensen R, Katsarava Z, Martelletti P, Stovner $L$ (2010) Lifting the burden: the first 7 years. J Headache Pain 11:451-455

4. Headache Classification Subcommittee of the International Headache Society (2004) The International Classification of Headache Disorders: 2nd edition. Cephalalgia 24(Suppl 1):9-160

5. Rasmussen BK, Olesen J (1992) Symptomatic and nonsymptomatic headaches in a general population. Neurology 42:1225-1231

6. Aaseth K, Grande RB, Kvaerner KJ, Gulbrandsen P, Lundqvist C, Russell MB (2008) Prevalence of secondary chronic headaches in a population-based sample of 30-44-year-old persons. The Akershus study of chronic headache. Cephalalgia 28:705-713

7. Diener HC, Limmroth V (2004) Medication-overuse headache: a worldwide problem. Lancet Neurol 3:475-483

8. Rasmussen BK, Jensen R, Olesen J (1992) Impact of headache on sickness absence and utilisation of medical services: a Danish population study. J Epidemiol Community Health 46:443-446

9. Latinovic R, Gulliford M, Ridsdale $L$ (2006) Headache and migraine in primary care: consultation, prescription, and referral rates in a large population. J Neurol Neurosurg Psychiatry 77:385-387

10. Ridsdale L, Clark LV, Dowson AJ, Goldstein LH, Jenkins L, McCrone P, Morgan M, Seed PT (2007) How do patients referred to neurologists for headache differ from those managed in primary care? Br J Gen Pract 57:388-395

11. Wiles CM, Lindsay M (1996) General practice referrals to a department of neurology. J R Coll Physicians Lond 30:426-431

12. Bekkelund SI, Albretsen C (2002) Evaluation of referrals from general practice to a neurological department. Fam Pract 19:297-299

13. Patterson VH, Esmonde TF (1993) Comparison of the handling of neurological outpatient referrals by general physicians and a neurologist. J Neurol Neurosurg Psychiatry 56:830

14. Olesen J, Steiner T, Bousser MG, Diener HC, Dodick D, First MB, Goadsby PJ, Göbel H, Lainez MJ, Lipton RB, Nappi G, Sakai F, Schoenen J, Silberstein SD (2009) Proposals for new standardized general diagnostic criteria for the secondary headaches. Cephalalgia 29:1331-1336

15. Kristoffersen ES, Grande RB, Aaseth K, Lundqvist C, Russell MB (2012) Management of primary chronic headache in the general population: the Akershus study of chronic headache. J Headache Pain 13:113-120

16. Olesen J, Bousser MG, Diener HC, Dodick D, First M, Goadsby PJ, Göbel H, Lainez MJ, Lance JW, Lipton RB, Nappi G, Sakai F, Schoenen J, Silberstein SD, Steiner TJ (2006) New appendix criteria open for a broader concept of chronic migraine. Cephalalgia 26:742-746

17. Silberstein SD, Olesen J, Bousser MG, Diener HC, Dodick D, First M, Goadsby PJ, Göbel H, Lainez MJ, Lance JW, Lipton RB, Nappi G, Sakai F, Schoenen J, Steiner TJ, International Headache Society (2005) The International Classification of Headache Disorders, 2nd Edition (ICHD-II)-revision of criteria for 8.2 Medication-overuse headache. Cephalalgia 25:460-465

18. Cephalalgia (2006) ERRATUM. Cephalalgia 26:360

19. Aaseth K, Grande RB, Benth JŠ, Lundqvist C, Russell MB (2011) 3-Year followup of secondary chronic headaches: the Akershus study of chronic headache. Eur J Pain 15:186-192

20. Sjaastad O, Fredriksen TA, Pfaffenrath V (1998) Cervicogenic headache: diagnostic criteria. The Cervicogenic Headache International Study Group. Headache 38:442-445

21. Benninger MS, Ferguson BJ, Hadley JA, Hamilos DL, Jacobs M, Kennedy DW, Lanza DC, Marple BF, Osguthorpe JD, Stankiewicz JA, Anon J, Denneny J, Emanuel I, Levine H (2003) Adult chronic rhinosinusitis: definitions, diagnosis, epidemiology, and pathophysiology. Otolaryngol Head Neck Surg 129(Suppl 3):1-32

22. Aaseth K, Grande R, Kvaerner K, Lundqvist C, Russell MB (2010) Chronic rhinosinusitis gives a ninefold increased risk of chronic headache. The Akershus study of chronic headache. Cephalalgia 30:152-160

23. Gossop M, Darke S, Griffiths P, Hando J, Powis B, Hall W, Strang J (1995) The Severity of Dependence Scale (SDS): psychometric properties of the SDS in English and Australian samples of heroin, cocaine and amphetamine users. Addiction 90:607-614

24. Lundqvist C, Aaseth K, Grande RB, Benth JŠ, Russell MB (2010) The severity of dependence score correlates with medication overuse in persons with secondary chronic headaches. The Akershus study of chronic headache. Pain 148:487-491

25. Norwegian Prescription Database (NorPD) (2011), http://www.reseptregisteret no/ Accessed 18 February 2011
26. Diamond S, Bigal ME, Silberstein S, Loder E, Reed M, Lipton RB (2007) Patterns of diagnosis and acute and preventive treatment for migraine in the United States: results from the American Migraine Prevalence and Prevention study. Headache 47:355-363

27. Lipton RB, Bigal ME, Diamond M, Freitag F, Reed ML, Stewart WF, AMPP Advisory Group (2007) Migraine prevalence, disease burden, and the need for preventive therapy. Neurology 68:343-349

doi:10.1186/1129-2377-14-5

Cite this article as: Kristoffersen et al: Management of secondary chronic headache in the general population: the Akershus study of chronic headache. The Journal of Headache and Pain 2013 14:5.

\section{Submit your manuscript to a SpringerOpen ${ }^{\odot}$ journal and benefit from:}

- Convenient online submission

$\checkmark$ Rigorous peer review

- Immediate publication on acceptance

- Open access: articles freely available online

- High visibility within the field

- Retaining the copyright to your article

Submit your next manuscript at springeropen.com 